\title{
MEMÓRIAS DE PROFESSORAS: TECENDO \\ CINECONVERSAS COM O INCRÍVEL EXÉRCITO DE BRANCALEONE
}

\section{REBECA SILVA BRANDÃO}

https://orcid.org/0000-0003-3739-8246

Prefeitura da Cidade do Rio de Janeiro

\section{ROSA HELENA MENDONÇA}

https://orcid.org/0000-0003-4778-3551

Universidade do Estado do Rio de Janeiro

\section{ROSSANA PAPINI}

https://orcid.org/0000-0002-4680-9070

Instituto do Noroeste Fluminense de Educação Superior / Universidade Federal Fluminense

Ao tecer cineconversas, com 0 incrivel exército de Brancaleone, três professoras atualizam o filme que traz, de forma satírica, entre outros temas, a peste negra, na Europa. As artes dos fracos e as táticas do fazer crer, questões pertinentes ao artigo e presentes na obra de Certeau, interessam às pesquisadoras que conversam através de experiências com o filme escolhido em função do paralelo com a Pandemia de 2020. As conversas com imagens e sons são problematizadas, a partir das ideias de Deleuze sobre cinema. 0 artigo possui três momentos: o primeiro traz lembranças de uma jovem (futura professora), que relembra o impacto causado pelo filme em sua estreia, em 1967, no Rio de Janeiro. A partir daí, são as reminiscências de uma professora, que usa o mesmo filme em projetos de Cinema e História, por volta dos anos 2000, que dão o tom à narrativa. Finalmente, uma terceira professora que não conhecia o filme, se propõe a assisti-lo e a pesquisar na internet matérias de divulgação e críticas, evidenciando uma prática de leitura cada vez mais frequente em nossos dias.

Palavras-chave: Memórias de professoras. Cineconversas. Cotidianos escolares. Redes educativas. 
ABSTRACT TEACHERS' MEMORIES: WEAVING

\section{'CINECONVERSATIONS' WITH BRANCALEONE'S ARMY (FOR LOVE AND GOLD)}

In weaving 'cineconversations' with Brancaleone's army (For Love and Gold), three teachers upgrade the aforementioned film that portrays in a satirical way, the black plague in Europe, among other themes. The so called 'art of the weak' and 'the tactics of make-believe', which are relevant issues in both article and film, are the researchers' interests: they interact with the film, through their experiences, making associations with the pandemic context of 2020. The conversations around images and sounds are tackled from the perspective of Deleuze ideas about films. This article presents three moments: the first brings the memories of a young girl (teacher-to-be) who recalls the impact the film caused when it was launched in 1967, in Rio de Janeiro. From such point, the second moment presents the reminiscences of a teacher who uses the same film around the year of 2000, setting the tone of the narrative. Finally, the third part shows the work of a teacher who, having not heard about the movie before, decides to see it and research articles and criticisms about it on the internet, which puts into evidence a very frequent reading practice of our times.

Keywords: Teachers' memories. 'Cineconversations'. School daily life. Educational networks.

\section{RESUMEN MEMORIAS DE PROFESORAS: TEJIENDO 'CINECONVERSACIONES' CON LA ARMADA BRANCALEONE}

Al tejer 'cineconversaciones', con La armada Brancaleone, tres profesoras 'actualizan' la película que satíricamente trata entre otros temas, de la 'peste negra' en Europa. Las 'artes de los débiles' y las 'tácticas para hacer creer a la gente', cuestiones pertinentes en este artículo y presentes en la obra de Certeau, son de interés para las investigadoras que hablan a través de las experiencias con la película elegida debido al paralelo con la Pandemia 2020. Las hablas con imágenes y sonidos se problematizan, con base en las ideas de Deleuze sobre el cine. El artículo tiene tres apartados: el primero presenta recuerdos de una joven (futura profesora), que recuerda el impacto causado por la película en su estreno, en 1967, en Río de Janeiro. A partir de ahí, son las reminiscencias de una profesora, que usa la misma película en proyectos de cine e historia, alrededor de 
la década de 2000, lo que marca la pauta de la narrativa. Finalmente, una tercera profesora que no conocía la película, propone verla y buscar en Internet materiales de difusión y crítica, mostrando una práctica de lectura cada vez más frecuente en la actualidad.

Palabras clave: Memorias de profesoras. 'Cineconversaciones'. Cotidianos escolares. Redes educativas.

\section{Introdução}

O cinema não apresenta apenas imagens, ele as cerca com um mundo. Por isso, bem cedo, procurou circuitos cada vez maiores que unissem uma imagem atual a imagens-lembrança, imagenssonho, imagens-mundo. (DELEUZE, 2005, p. 87)

O cenário das ruas, em março de 2020, parecia "coisa de cinema". Quem poderia imaginar, de uma hora para outra, ruas vazias, escolas, universidades, cinemas, teatros, museus, comércio, em geral, fechados? Que a população, em sua grande maioria permaneceria isolada em casa? Estávamos acompanhando pela TV, jornais, internet, cenas assim na China, e depois na Itália, até que o novo coronavírus (SARS-CoV-2) se alastrou mundo afora e chegou aqui no Brasil onde há uma enorme desigualdade social, uma crise política sem precedentes, aliada ao modo como culturalmente nos relacionamos pelo toque, por abraços e beijinhos, embora nem sempre tão carinhosos assim, para lembrar a canção ícone da Bossa Nova, "Chega de saudade", de Tom Jobim e Vinícius. Como enfrentar a pandemia, de que modo dar sequência às atividades, em especial, no nosso caso, àquelas ditas letivas? Os desafios foram muitos: usar as redes sociais, experimentar novas formas de comunicação, em meio a debates acalorados sobre as desigualdades de acesso às tecnologias, num país tão distante da equidade.

Se o real nos pareceu "coisa de cinema", evidenciando que, um filme não reproduz, mas cria realidades (DELEUZE, 1985, 2005), nada nos pareceu tão oportuno quanto usar o cine- ma como "personagem conceitual" (DELEUZE; GUATTARRI, 1992) - prática fundamental em nosso grupo de pesquisa - para criar, a partir de memórias, uma narrativa, tangenciando questões relativas à pandemia. Fizemos isso, com a intenção de potencializar devires criadores, recorrendo ao clássico L'armata Brancaleone (1966), em português: O incrivel exército de Brancaleone. As razões da escolha irão se evidenciar ao longo do artigo.

Trazemos, neste texto, memórias de três professoras-pesquisadoras, entendendo que estas podem ser tecidas através de agenciamentos e rizomas, o que no grupo de pesquisa ao qual somos vinculadas chamamos de "redes". São rememorações (auto)biográficas que se cruzam em fios que tecem, com o uso do cinema e de vozes de autores ligados, em especial, às pesquisas com os cotidianos, uma narrativa que problematiza a potência das conversas na formação de professores e as "artes do fraco" como "táticas" de criação. Partimos da ideia de que o movimento biográfico em Educação tem pontos de aproximação com as pesquisas com os cotidianos: as histórias de vida, as trajetórias e as experiências que, sendo individuais, se complementam em outras histórias - em suas singularidades e recorrências - são evidências dessa proximidade. A perspectiva de que as narrativas são criações que não pressupõem um sentido de verdade é também um ponto em comum, entre alguns outros. Não se trata, no entanto, de estabelecer comparações entre as duas pers- 
pectivas prático-teóricas ${ }^{1}$ de pesquisar, mas de buscar convergências nas narrativas que são tecidas a partir das memórias e das conversas em ambas as perspectivas teóricas, no que diz respeito, em especial, à formação de professores.

Tomamos, assim, como "personagem conceitual" - ou intercessor - para as nossas conversas - conceito trazido para as pesquisas com os cotidianos - um filme: $O$ incrivel exército de Bancaleone. As lembranças de uma jovem, que nunca se esqueceu do impacto causado pelo filme em sua estreia, em 1967, num Rio de Janeiro que inspirava ares de arte e cinema e começava a exalar gases tóxicos de uma ditadura, dão início à narrativa. A partir daí, são as reminiscências de uma professora de História, por volta dos anos 2000, que dão o tom à narrativa. 0 mesmo filme é usado para a criação de projetos envolvendo Cinema e História e essa experiência é contada no texto. Finalmente, uma terceira pesquisadora que não conhecia o filme, se propõe a assisti-lo e a empreender uma pesquisa na internet por críticas e matérias de divulgação, evidenciando uma prática cada vez mais frequente em nossos dias, ampliada no contexto de isolamento físico imposto a muitos pela pandemia da COVID-19, que é o uso das redes sociais e dos mecanismos de busca virtual para empreender contatos, pesquisas e tecer rizomas.

Debruçarmo-nos sobre esse filme, para nós, significou mergulhar num passado ontológico, o que Deleuze (2005) diz ser possivel através das "imagens-tempo" do cinema, ou seja, mergulhar num "virtual", numa dimensão diferente organicamente do "real". Para Deleuze, a realidade "virtual" não é menos "real" por ser "virtual". Bergson e Deleuze nos ensinam

1 A dicotomia, própria da construção da ciência na Modernidade, é entendida como limite para nós que trabalhamos em pesquisas nos/dos/com os cotidianos. Por esse motivo, optamos por escrever as palavras desse modo: juntas, em itálico e com aspas simples, para indicar que são termos indissociáveis. que "existe um passado contemporâneo ao presente" (GUÉRON, 2011, p. 182). Guéron nos mostra como é mais simples do que parece: "o sentido de uma palavra é seu passado, o sentido de uma imagem é o seu passado [...]. Para compreender algo, instalamo-nos subitamente num passado" (Idem, p. 183). Guéron continua explicando que "este passado, que estamos chamando de 'virtual', é na verdade uma potência de vida não orgânica que constitui o mundo. Ele é como afeto do tempo no corpo, no orgânico que, por sua vez, nós designamos como 'atual'" (Idem, p. 183).

\section{Uma jovem vai ao cinema e enfrenta os cotidianos}
Volver a los diecisiete
Después de vivir un siglo
Es como descifrar signos
Sin ser sabio competente
Volver a ser de repente
Tan frágil como un segundo
Volver a sentir profundo
Como un niño frente a Dios
Eso es lo que siento yo
En este instante fecundo.

(Volver a los 17 - canção de Violeta Parra, imortalizada por Mercedes Sosa)

Vamos começar com reminiscências de uma jovem estudante secundarista - atual ensino médio - do Colégio Pedro II, que tinha à época 17 anos. E, para relativizar a noção de tempo, hoje é a mais velha do trio que se propôs a conversar aqui, entendendo as conversas como metodologia de pesquisa e lócus principal do trabalho.

Podemos dizer que as conversas quando, de fato, acontecem, teriam essa potência de colocar sob suspeita nossos clichês-opiniões-verdades, empurrando-nos para os limites de nossas crenças-valores, ao nos forçar a pensar com outras referências os acontecimentos vividos nos cotidianos de nossas vidas. É como se esti- 
véssemos, durante as nossas conversas, vivendo, sempre, questões que insurgem em meio às linhas de multiplicidades que nos compõem (ALVES, FERRAÇO, 2018, p. 58-59).

O ano era 1967, no Brasil vivíamos sob o regime de exceção imposto pelo golpe político-militar, deflagrado em março de 1964. Havia ainda um resquício de liberdade de expressão que o bipartidarismo - Aliança Renovadora Nacional (ARENA) e Movimento Democrático Brasileiro (MDB) - parecia legitimar. 0 endurecimento radical do regime viria em 1968, com a decretação do Ato Institucional no 5 (Al-5), que implementou, de forma drástica, a perseguição aos adversários do regime e a censura aos meios de comunicação e às expressões artísticas em geral.

Para pensar os espaços-tempos atuais em que atravessamos uma pandemia e as novas formas de aprender-ensinar suscitadas nesse período, recorremos ao cinema e a sua potência nas diferentes redes educativas que formamos e que nos formam. Fazemos uso (DE CERTEAU, 1994) de filmes, em sessões que denominamos de "cineconversas", que podem ser entendidas como conversas que se dão a partir de filmes que trazem questões sociais. "As questões sociais se transformam em questões curriculares" e esses movimentos são alvo de nosso interesse (ALVES, ANDRADE, CALDAS, 2019). No atual momento, a pandemia assume lugar relevante nas discussões. Cabe lembrar que tudo isso é feito sem desconsiderar as características da linguagem cinematográfica, é claro. Mas, como os filmes que abordam a COVID-19 e seus impactos serão ainda produzidos, buscamos usar outros que permitam analogias. Tem sido assim também na escrita de textos em coautoria. Se uma criação parte de uma ideia e de conversas em torno dela, escolhemos um filme, depois de pensar em vários, para nos ajudar a tecer o artigo em que buscamos problematizar questões como currículos, conversas, cinema e formação docente. E o fizemos de várias maneiras possibilitadas pelo "estar junto" virtual.

A escolha recaiu sobre $O$ incrivel exército de Brancaleone, lançado na Itália em 1966 e no Brasil em 1967, como já mencionado, uma comédia-satírica italiana, com direção de Mario Monicelli e estrelada por Vittorio Grassman, Gian Maria Volonté, Catherine Spaak, entre outros. Por que motivo? Na verdade, foram várias as razões:

O enredo versa sobre as aventuras de uma cavalaria medieval maltrapilha que, inspirada nas aventuras de Dom Quixote, avança contra os moinhos de vento que, no caso, são a denominada "peste negra" e os "inimigos bárbaros" (sarracenos e bizantinos). O sistema feudal e os poderes da igreja católica são desafiados pelos despossuídos naquela época que ficou conhecida como Idade Média, numa Europa devastada pela pandemia, pela fome e pela guerra, de forma quixotesca e, a partir do filme, "brancaleonesca". Já que Brancaleone é uma espécie de Don Quixote, às avessas.

A analogia com o que vivemos, nos chamados anos de chumbo no Brasil e, lamentavelmente, com o que se passa hoje - ameaças à democracia agravadas pela crise profunda acirrada pela pandemia - é evidente. Nesse sentido, a expressão "O incrivel exército de Brancaleone" há muito se desprendeu do filme e vem sendo utilizada, há gerações, metaforicamente para exprimir a luta dos fracos contra os poderosos. É Certeau que nos ajuda a pensar nas táticas (e astúcias), com o que chama em seus estudos de "a arte do fraco".

0 poder se acha amarrado à sua visibilidade. Ao contrário, a astúcia é possível ao fraco, e muitas vezes, apenas ela, como 'último recurso': (Quanto mais fracas as forças submetidas à direção estratégica, tanto mais esta estará sujeita à astúcia. Traduzindo: tanto mais se torna tática (DE CERTEAU, 1994, p. 101). 
A estreia de $O$ incrível exército de Brancaleone, no Brasil, ocorreu no ano seguinte ao lançamento na Itália e em outros países europeus e vamos conversar de início sobre a publicação, nos jornais do Rio de Janeiro, de cartazes (Figura 1), sinopses (Figura 2), críticas (Figura 3) e divulgações de exibição do filme, notadamente no Correio da Manhã, jornal considerado de oposição ao regime militar e que viria a ser extinto em 1974, ainda na ditadura, regime que só iria se abrir em 1985, com a eleição indireta de Tancredo Neves, tendo José Sarney como vice. Sarney assumiu o poder, uma vez que Tancredo morreu antes da posse.

A possibilidade de empreender essa pesquisa ao acervo da Hemeroteca - disponivel on-line - proporcionou o encontro com as memórias das primeiras exibições do filme no Brasil, evidenciando ainda o destaque que os jornais davam aos lançamentos cinematográficos e a importância desses na vida cultural da cidade, no caso o Rio de Janeiro. Trazer essas imagens é um modo de evidenciar memórias de uma forma de divulgação do cinema ao público, que persiste de alguma maneira na contemporaneidade, ainda que sem o mesmo protagonismo, já que existem tantos outros meios de divulgação que podem ser acessados e também outras possibilidades de assistir aos filmes, sem ter que aguardar as estreias nas salas de cinema. Consideramos que essas figuras, tanto quanto o filme em questão, operam como "personagens conceituais" (DELEUZE; GUATTARI, 1992), uma vez que elas mobilizam nossos pensamentos e nossas memórias. Quanto à memória, segundo De Certeau (1994, p. 162-163, grifo do autor),

Ela se constrói ao contrário de acontecimentos que não dependem dela, ligada à expectativa de que vai se produzir ou de que deve se produzir algo de estranho ao presente. Longe de ser o relicário ou a lata de lixo do passado, a memó- ria vive de crer nos possiveis e de esperá-los, vigilante, à espreita.

Foi nessa perspectiva trazida por Certeau, de que o passado não está descartado numa "lata de lixo" ou num "relicário", que o filme surgiu como possibilidade para duas de nós, a princípio, de criar conhecimentos-significações acerca do momento pandêmico de 2020. Foi como se a memória do filme estivesse "à espreita" para retornar às conversas. De que maneira um filme lançado há tantos anos retornou à memória como possibilidade de criação? Quais seriam os fios que teceram essa ideia? Em primeiro lugar, a razão mais evidente foi a possibilidade de comparação da peste, que grassou na Idade Média, com a pandemia da COVID-19 que surpreendeu o mundo inteiro no inimaginável ano de 2020. Outra razão é a noção "do fraco" - do incrivel exército de maltrapilhos - enfrentar o poder instituído. Isso remonta não só o momento atual, mas também ao período de estreia do filme, em que vivíamos sob um regime ditatorial, como já mencionado. Outras associações foram se evidenciando ao longo das conversas e da criação deste artigo.

No texto do jornal, Figura 2, podemos perceber nos parênteses (se os energúmenos da Censura não cortaram) e (se a Censura em sua conhecida estupidez, não mutilou) (grifos nossos), que ainda havia, apesar da Censura, espaço para as manifestações contrárias ao sistema. Os cartazes, assim como as críticas e sinopses, revelam a arte gráfica própria de uma época e também o modo como determinadas críticas eram feitas com intuito de criticar não só os filmes como o próprio regime, criando analogias que provocavam reflexões nos leitores e, de certa forma, instigavam apropriações da obra, correlacionando-a com os tempos de repressão que se anunciavam e que efetivamente já eram vividos. 
Figura 1 - Cartaz do filme, entre outros, na edição de 22 de junho de 1967, quando o filme emplacava a segunda semana em cartaz

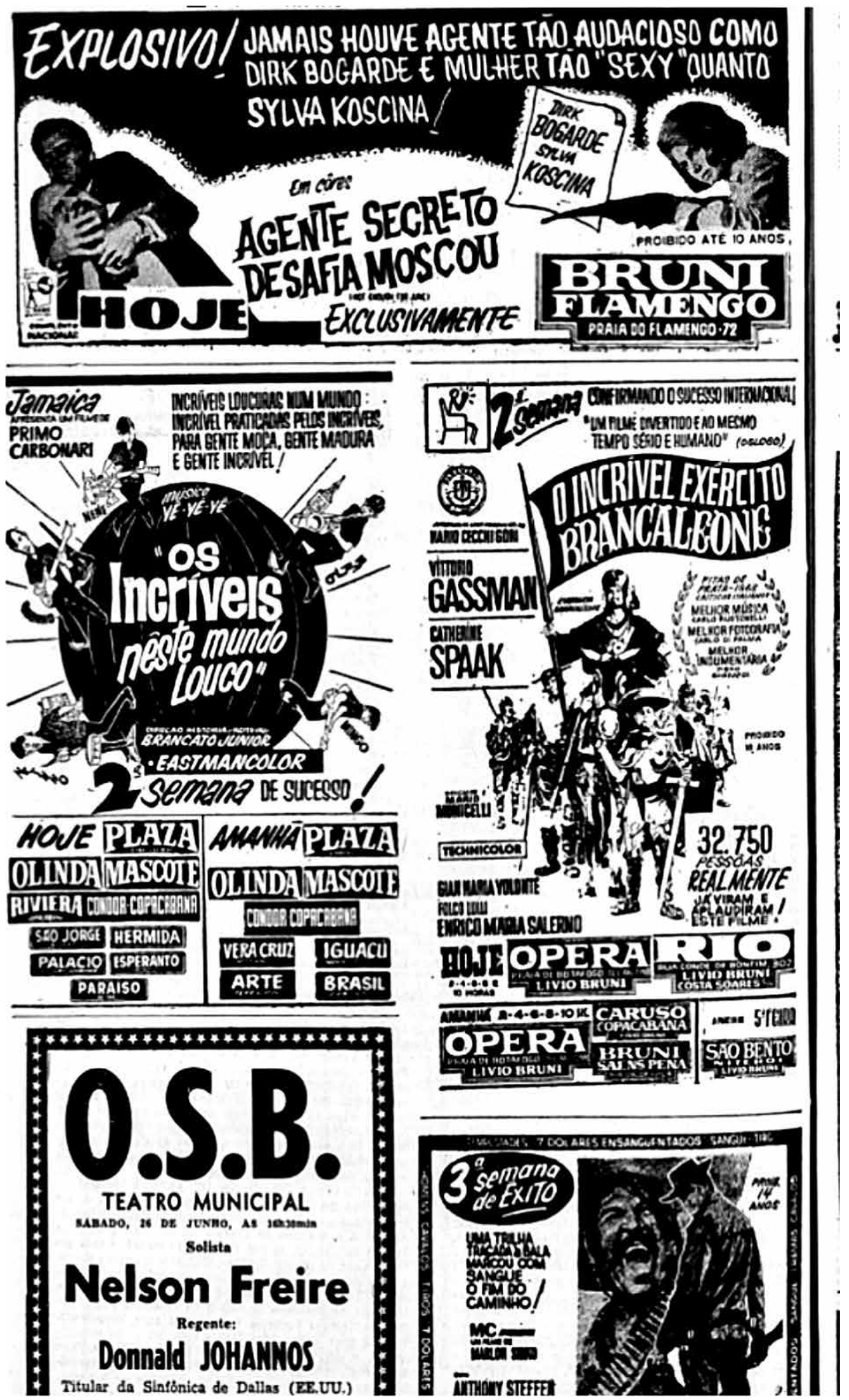

Fonte: Hemeroteca da Biblioteca Nacional. Disponivel em: https:/ / bndigital.bn.gov.br/hemeroteca-digital/. Acesso em: 13 jul. 2020. 
Vejamos agora, outra figura:

Figura 2 - Sinopse do filme, na edição do Correio da Manhã, 11 de junho de 1967

\section{O incrivel Exército Brancaleone (L'Armatta Brancaleone)}

Este filme vem muito bem recomendado pela critlca européia. Obteve os prêmlos Fita de Prata de 1966, concedidos pelos comentaristas italianos, à melhor música, de Carlo Rustichelli; à melhor fotografia cm côres, do Carlo di Palma; melhor indumentária, de Plero Gehrardi. Trata-se de uma sátira, em duas horas o dez minutos (so os energúmonos da Censura não cortaram), aos heróls medievals, à cavalaria, a concelto de nobreza predomlnante no ano 1000, na Itália, devastada o saqueada por hordas do sarracenos, Vittorio Gassman, dizem as referênclas em que nos baseamos, interpreta admiràvelmente uma espécle de Dom Quixote, um cavaleiro de Tristo Figura, coração puro e braço valente, pobre de marrémarró-marrob, que monta sua única posse, o pálido cavalo Aqullante. Ele é Brancalcone e constitul um exército para conquistar um feudo nas Apúleas, um exćrcito de aventureiros desmoralizados. Daf, acontecem as aventuras mais engragadas, mals estapafúrdias que se possa imaglnar. Duelos, conquista do cldades onde a praga empesta (moinhos de vento?), encontro com peregrinos que so dirigem à Terra Santa, resgate de damas, e uma sequiência de bacanal sado-masoquista numa córto bizantina (se a Censura em sua conhecida estupidez, nảo mutllou). Ao lado do Gassman, flguram Catherine Spaak, Enrico Maria Salerno, Folco Lulli, Marla Grazla Buccella (que interpreta a bizantina sádica, a se despir e a açoitar o pobre Brancalcone), Barbara Steele, Gian Maria Volonté e outros. Argumento e rotelro do Age \& Scarpelll e direção do scguro Mario Monicelli, que já nos deu o inesquecivel Os Companholros. (Fair Film, da Itália \& Les Films Marceau, de França/Paranaguá Clnematográfica).

Fonte: Hemeroteca da Biblioteca Nacional. Disponível em:https:// bndigital.bn.gov.br/hemeroteca-digital/. Acesso em: 13 jul. 2020.
Conforme o cartaz da Figura 1, o filme estreou em 15 de junho de 1967, no cinema Condor-Copacabana, tendo seguido em cartaz no cinema Bruni-Copacabana, no mês de julho do mesmo ano, isso para ficar num único bairro, já que os filmes costumavam ser distribuídos simultaneamente em diferentes locais na cidade que possuía, então, uma grande quantidade de cinemas de rua (quase 200 cinemas). É interessante observar que cada filme era exibido em cinco sessões diárias, a partir das 14h, em geral, até a última sessão, às 22h. Hoje são aproximadamente 20 os cinemas de rua no Rio de Janeiro e a maioria das salas se concentra nos shoppings, com horários alternados. Mas essa é uma outra história. Com o advento das fitas VHS, seguidas dos DVDs, YouTube, sites de downloads e dos sistemas streaming, muitos filmes podem ser vistos em casa, nas escolas, universidades, em diversos cineclubes etc. 0 filme em questão foi assistido no Bruni-Copacabana, por uma das autoras, no mês de julho de 1967, durante as férias escolares, período em que os estudantes costumavam lotar as salas de exibição nas sessões vespertinas. A prática das cineconversas já existia, não com esse nome, tampouco com os propósitos que atribuímos atualmente à atividade no grupo de pesquisa. Consistia, no entanto, em conversas que aconteciam após o filme, em geral, em um 
bar ou lanchonete, ou mesmo em algum espaço público, como a orla ou uma praça. Depois de 1968, esses encontros nas ruas passaram a ser considerados suspeitos e eram evitados, passando a acontecer na casa de alguém do grupo, por exemplo.

Os filmes eram avaliados pelos críticos dos jornais (ainda hoje são) e, como podemos ob- servar na Figura 3, Brancaleone não foi de imediato um sucesso de crítica, mas sim de público. $O$ que ampliou seu tempo de exibição foi a propaganda boca a boca e a quase imediata apropriação do seu título como expressão de grupos que se insurgiam, ainda que com poucos recursos e certo grau de idealismo, contra o poder instituído pela ditadura.

Figura 3 - Crítica do filme, na edição do Correio da Manhã, 18 de junho de 1967

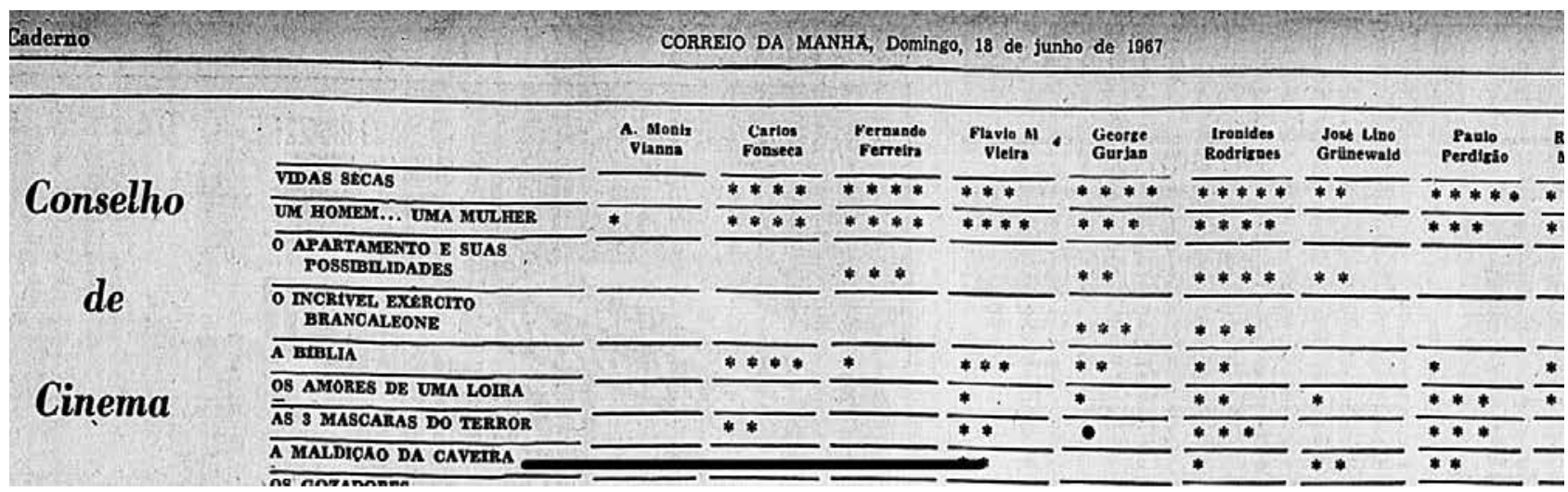

Fonte: Hemeroteca da Biblioteca Nacional. Disponível em: https://bndigital.bn.gov.br/hemeroteca-digital/. Acesso em: 13 jul. 2020.

Vale destacar que a música tema do filme, "Armata Brancaleone", tinha um refrão contagiante, que logo caiu no agrado popular:

\section{Branca, branca, branca}

Leon, leon, leon,

Era assim que muitos se expressavam quando marchavam ao encontro das causas que consideravam justas, num misto de enfrentamento e deboche ao militarismo que se impunha como valor e força. É claro que a referência é, sobretudo, aos grupos que faziam oposição ao regime. Com o passar do tempo, no entanto, o já difundido bordão "O incrivel exército de Brancaleone" foi sendo incorporado ao vocabulário, usado em muitos outros setores da vida, ganhando a metáfora função retórica de metonímia, ou seja, despregada de seu contexto semântico original como título de um filme, a expressão, mesmo para quem não conhecia a película, passou a significar algo como "o povo unido, jamais será vencido" e, portanto, Avante!

Essas conversas suscitaram outras reminiscências, ampliando as redes educativas nas quais cada uma de nós, as autoras, nos formamos e assim partimos para outras lembranças. Seguindo com Certeau, cientes de que "como os pássaros que só põe seus ovos no ninho de outras espécies, a memória produz num lugar que não the é próprio" (1994, p. 162). Coube a nós, as autoras, tecer os fios das memórias, cerzindo experiências diversas num único ensaio.

\section{Brancaleone e nossas incriveis peripécias: histórias de vida e cotidianos escolares}

Nesta parte do desenvolvimento do artigo, procura-se narrar uma pequena e importante parte da história de vida de uma das autoras. 
É também uma forma de devir-criação, de potencializar a existência dentro do atual contexto da pandemia do coronavírus, que estanca parcialmente nossos cotidianos, produzindo estranhas inércias, paralisias, mas também movimentos. Conseguir algumas vezes romper - ainda que virtualmente - esse quadro, conversar, escrever, trocar impressões sobre o vivido já é uma forma de ir além, sair de certo vazio e ir recriando a vida.

Esta história se passa ao meio das últimas duas décadas. Naquela época, o retorno à sala de aula, após alguns anos como gestora numa secretaria de educação trazia liberdade de volta à professora. A ida para uma periferia longínqua ${ }^{2}$, longe do "poder central", dos holofotes, das brigas políticas, tanto internas quanto externas, envolvendo a cidade, como que ficaram para trás. Naquela altura, a professora já se encontrava extenuada com todo um processo e sentia que já era hora de procurar outros rumos e, principalmente, de cuidar de si, se refazer, se reinventar.

Naquela época, as vivências profundas na floresta, o Parque Nacional da Serra da Bocaina, que circunda o bairro no qual estava a escola foram essenciais. Uma cadeia de montanhas, o "paredão" (como chamam os nativos) da Serra do Mar, exuberante, parecia que estava esperando, em forma de refúgio. Talvez por lembrar sua infância, a liberdade em meio à natureza, a exploração e as descobertas sem fim nos caminhos da floresta que a acalmavam e eram como um ninho.

É curioso ressaltar que esse movimento rumo ao "mato", ao verde, aos rios e mares, às cidades pequenas, vilas, tem sido empreendido por uma parte das pessoas que hoje tem ou cria essa possibilidade durante a pandemia. Vale destacar também que, atualmente, a internet já está acessivel em muitos desses lu-

2 A Escola Municipal Nova Perequê, fica distante uns 50 quilômetros do distrito sede, a cidade de Angra dos Reis, em direção à Paraty. gares e é um grande diferencial da experiência de isolamento e busca vivida, naqueles idos, pela professora em questão.

Ela crê que conseguiu, com essas vivências, escapar de algo terrivel, uma sensação de aniquilamento que rondava seu ser. Imaginário e fantasia, além de uma infância feliz, talvez tenham ajudado. Morar numa casinha era um alento - $A$ casa na floresta ${ }^{3}$ era um livro inesquecível que sua mãe lia para as crianças sobre uma família de migrantes que enfrentava rigores para refazer seu destino -, bem como pescar camarões e lambaris subindo e descendo os rios encachoeirados, pois lá a área é relativamente montanhosa, com vários platôs e grandes ilhas fluviais, cultivada por pequenos posseiros que investem numa agricultura de subsistência, sendo o principal produto a banana. Devaneava como tantos que no passado migravam, largaram mundos e se adaptaram a uma natureza vibrante. Sentia-se recomeçando.

0 exílio na Bocaina foi fundamental para essa reinvenção. Foi algo intimista, profundo, uma conexão à infância, quando, livre, andava à solta por mares e lagoas, numa relação telúrica com a natureza e a cultura. Um convívio mais estreito com famílias de camponeses, algumas de pais de alunos, pessoas incriveis em sua simplicidade e sabedoria. Este é um paradoxo: por caminhos tortuosos, esse exílio foi uma reconexão com o essencial da vida.

Essas são falas que se aproximam, de certo modo, do que temos ouvido amiúde: o mundo não será o mesmo depois da pandemia. Os valores estão mudando, estamos vivendo com o

3 Aqui uma observação, na infância desta autora, a sua mamãe e as tias eram grandes leitoras, e havia alguns livros mais marcantes sobre vivências nas florestas, na natureza, como a obra de Laura Elizabeth Ingalls Wider (1867-1957), escritora americana de livros infantojuvenis autora da série Os Pioneiros, na qual conta as aventuras vividas por sua família na colonização do oeste, uma saga composta de vários livros, como o citado $A$ casa na floresta (1963), além do Às margens da lagoa prateada (1963), que ela associava sempre à lagoa. 
essencial, muitas coisas foram ressignificadas pela ameaça à vida... Verdades por um lado, essas frases são questionáveis em um modelo de capitalismo voraz que insiste em dicotomizar saúde e economia.

A professora, em seu pertencimento à escola, e que, durante aqueles anos foi se refazendo com o auxílio da natureza, para onde sempre retorna (assim como outros) na procura do seu "eu" mais íntimo, de um equilíbrio necessário à vida, traz aqui a memória desses importantes encontros.

Nessas trilhas do magistério, muito foi aprendido. Procurar ser capaz de se situar além do imediato, abrir-se à pluralidade, aos múltiplos sentidos da realidade foi o que prevaleceu.

Durante aquele tempo, o envolvimento com vários projetos da escola foi marcante. Trazemos, nessas lembranças, um pouco de um deles, que levou a vários estudos e produções. A Festa Literária da Nova Perequê (Flinp), inspirada na Festa Literária Internacional de Paraty (FLIP), é até hoje um importante acontecimento escolar, cercado de atividades culturais. 0 evento ocorre já há vários anos com sucesso, envolvendo toda a escola em produções que incentivam a leitura e a escrita.

Vários projetos foram criados nos espaçostempos da Flinp. A narrativa de uma professora de História procura trazer aqui ações com turmas nos primeiros anos do segundo segmento do ensino fundamental, chamado agora de "anos finais".

Acreditando na valorização de memórias docentes e não querendo perder de vista algumas produções no campo da pesquisa (auto) biográfica, sobre o domínio da profissão docente, buscamos inspiração nas autoras Passeggi e Barbosa

[...] conhecemos por nossa própria experiência seus dilemas e tateamentos e, ao tomarmos consciência disso, somos estimulados a deli- near cenários investigativos que, ao invés de se pautarem na construção de modelos abstratos de atuação profissional, procurem tornar visíveis a 'vida viva' dos professores, que guarda segredos sobre o complexo exercício da docência (PASSEGGI; BARBOSA, 2008, p. 10).

Essa narrativa estaria num campo de memórias coletivas, apesar de apontar para subjetividades, suas trilhas e singularidades, pois

[...] como vimos, cada memória é única, tem a marca e é constitutiva de nossa identidade, fazendo parte, simultaneamente, das comunidades restritas ou ampliadas das quais participamos; ligando-nos também às memórias comuns, sócio-históricas. Ao trabalharmos com as histórias dos sujeitos, como narrativas, ficam evidentes as lembranças individuais entrelaçadas às memórias coletivas, também como parte da memória histórica que as contextualiza (BRANDÃO, 2008, p. 16).

Apesar de submetidos a processos de controle e seriação, temos esses "praticantes anônimos" a desenvolver suas táticas, "sem sair do lugar onde tem que viver e que the impõe uma lei, ele aí instaura pluralidade e criatividade" (DE CERTEAU, 1994, p. 93). Assim, o uso do filme $O$ incrivel exército de Brancaleone permitiu encontrar um manancial de criações e de encantamentos sem fim. A procura por montar uma "dvdteca" especial, personificada, adequada ao ensino de História e às várias faixas etárias era um dos objetivos. 0 empenho pessoal da professora se revelou ao viajar ao Rio de Janeiro, a procura de adquirir filmes que pudessem dinamizar alguns projetos e tornar mais interessantes as aulas.

Brancaleone foi um achado. Tinha grande recepção entre os adolescentes, inspirava. Naquele tempo, em meados das últimas duas décadas, a docente trabalhava com a ideia de imaginário e educação. Pretendia que os estudantes associassem determinado imaginário a uma época, neste caso, à Idade Média. Havia aulas preparatórias contextualizando o assun- 
to, utilizando o livro didático e outros artefatos, e depois se assistia a dois filmes por semestre, muito aguardados pelas turmas.

Desses experimentos de criação curricular, advinha uma produção artística com desenhos de cavaleiros andantes - com ou sem armadura -, castelos, dragões, densas florestas, cidades muradas, fortificadas, espadas encantadas ou não, várias situações da vida cotidiana da época etc.; refinávamos a produção a partir de um arquivo com desenhos a bico de pena que eram ampliados; vários alunos preferiam a criação livre, outros decalcavam ou "tiravam" desenhos de fontes diversas, inclusive com pesquisas na biblioteca escolar ${ }^{4}$. A professora comprava materiais de boa qualidade, papel A3, cadernos especiais de desenhos, lápis de cor, giz de cera etc. A escola pública ficava numa longínqua periferia e os educandos eram menos favorecidos economicamente. Esses procedimentos, essas manualidades, possibilitaram descobertas incriveis.

Brancaleone, os alunos, os painéis para a Flinp estão inscritos para sempre nas memórias dessa professora que não consegue pensar o filme longe desses acontecimentos. São memórias afetivas. Assim como as memórias da juventude da autora que inicia este artigo, trazendo suas impressões sobre o lançamento do filme nos idos de 1967.

Já se fazia trabalhos com filmes, mas era necessário produzir resultados palpáveis para a Flinp. Fizemos, com turmas diversas, vários tipos de painéis temáticos, sendo que a maioria girava em torno da história local. Houve a produção de livros artesanais na Educação de Jovens e Adultos (EJA), com a história de vida dos alunos, junto ao mar e à floresta, pois o bairro encontra-se entre o oceano, um peque-

4 No período em que se deram essas atividades, não era frequente o hábito de fotografar todo o processo pedagógico. Esse material provavelmente existe na escola, mas em meio à pandemia não foi possível localizá-lo. no vale de planície aluvial e os paredões da Serra do Mar, pertencentes ao Parque Nacional da Serra da Bocaina. Havia também saraus com fogueiras e contação de histórias, mas aí já é outra história...

Esses painéis eram artesanais, colagem de desenhos sobre cartolinas nos cavaletes de madeira. A professora considerava que conseguia a livre associação entre as ideias, os conteúdos de uma época e seu imaginário e para isso nosso cavaleiro andante, Brancaleone, cumpria um papel e tanto ao nos ajudar a criar currículos nos cotidianos escolares.

Outra importante questão era quando trazíamos tal imaginário para nossa época e procurávamos mostrar como este estava presente, numa metamorfose, em parte da ampla produção audiovisual de nosso tempo, em outros filmes, nos games, nos álbuns de figurinhas - o que constituía todo um capítulo a parte, com eles a explicarem mil personagens fabulescos dos que colecionavam. Assim, o passado não estaria só lá, quietinho, mas "andava por aqui", como diziam os discentes.

Quanto à peste, um assunto espinhoso, colocado pela saga humana no tempo e enredo forte no filme, era tema tratado em várias aulas, mas a maioria achava que isso era coisa de antigamente, das calendas, de tempos míticos. $O$ velho dito que a história quer sempre lembrar aquilo que os homens querem esquecer. O ensino de História e seus desafios...

$\mathrm{Na}$ coleção de filmes, $O$ incrivel exército de Brancaleone era um dos prediletos, pelo sucesso junto aos estudantes, pela energia contagiante que emanava e pela alegria. Como já referido, a Flinp surgiu sob influência direta da FLIP de Paraty. A escola mencionada fica em Mambucaba, na divisa com Paraty. Foram várias excursões à Flipinha, outro grande encontro e, dessas magias encantatórias, surgiram mil ideias incriveis que tornaram o festival escolar famoso na Rede Municipal de Ensino, 
inspirando o surgimento de vários outros.

A sala de vídeo era outro caso à parte. Com os anos, os docentes foram equipando a sala e a tornando aconchegante, um "cineminha", com cortinas escuras, bom mobiliário etc. Mas cada vez que vinham novas formações de turmas, um novo ano letivo, havia pressões do governo municipal de transformá-la numa sala de aula comum, tentando tirar sonhos, produções e socializações de mundo com os alunos. Resistia-se bravamente. A sala de vídeo era uma árdua conquista, algo que precisava estar sempre, quixotescamente, "brancaleonamente", protegida...

Essas memórias, suas vivências e narrativas estão numa fruição, fazem parte de um percurso na educação, no fazer-se professora, e acreditamos junto a Bragança (2012, p. 63-64) que

[...] a formação é um processo interior; liga-se à experiência pessoal do sujeito que se permite transformar pelo conhecimento. Logo, podemos afirmar que, potencialmente, todos os espaços e tempos da vida são espaços e tempos de formação, de transformação humana [...]. O conhecimento como expressão da existência humana [...] exige parar a 'aceleração' da vida cotidiana, o ritmo cronológico e se permitir voltar sobre si mesmo, fortalecendo os fios que, em cada ciclo de nossa vida, dão sentido à existência. Mas, ao mesmo tempo que, nesse movimento, reencontramos a nós mesmos, abrimo-nos ao outro, ao universo. Nesse sentido, Josso (2002, p. 66-80) perspectiva a formação como busca vital, saber-viver, busca de si e do nós, da felicidade, do sentido e do conhecimento.

Aquele tempo na escola foi um mergulho no papel de professora-pesquisadora, marcando a trajetória docente. Consideramos que este relato se insere no campo das histórias de vida, que seria

[...] uma denominação genérica em formação e em investigação, visto que se revela como pertinente para a autocompreensão do que somos, das aprendizagens que construímos ao longo da vida, das nossas experiências e de um processo de conhecimento de si e dos significados que atribuímos aos diferentes fenômenos que mobilizam e tecem a nossa vida individual/coletiva (SOUZA; RIBEIRO, 2010, p. 82).

Procuramos aqui contar uma história, a história de espaços-tempos locais, vivenciada por professores e professoras nos seus deslocamentos, na sua busca por melhores condições de vida e de exercerem o magistério com mais liberdade. Uma história também da educação, de seus múltiplos percursos, de seus sonhos e implicações, de sua busca por sentido, em vários projetos/produções com os cotidianos escolares (ALVES, 2008).

\section{Tecendo rizomas com 0 incrivel exército de Brancaleone nas redes virtuais}

A fabricação dos simulacros fornece assim o meio de produzir crentes e portanto praticantes (DE CERTEAU, 1998, p. 287).

O contato da terceira professora com esse filme se deu através das outras colegas autoras deste artigo, quando conversavam sobre filmes que poderiam remeter à pandemia de 2020. A essa altura, o filme, que tem mais de cinquenta anos, trazia angústias presentes ainda hoje, como os apresentados na sátira aos seguidores religiosos em busca da cura para peste numa jornada desenfreada à Terra Santa. Essa marcha dialoga com as "táticas de fazer crer" suscitadas por Certeau (1994), às quais buscaremos dar enfoque. 0 segundo passo se deu através de busca nas redes da internet, com a finalidade de assistir ao filme. Essa busca pelo encontro do título correto ${ }^{5} \mathrm{e}$ por uma versão legendada tornou a pesquisa

5 O incrivel exército de Brancaleone. Filme dirigido por: Mario Monicelli. Itália, 1967, colorido, 124 min. Disponivel em: https: / / www.youtube.com/watch?v=lCzHOLMRs98. Acesso em: 20 jul. 2020. (Filme). 
mais específica e provocou um mergulho no universo do filme, através das narrativas de outros praticantes-pensantes ${ }^{6}$ presentes na internet, antes mesmo de assistir ao filme.

A tropa de Brancaleone, após tomar conhecimento da existência da peste, quando encontra um vilarejo dizimado pela doença, é surpreendida por uma romaria liderada por um religioso que os convence a segui-los à Terra Santa em busca da cura. Nas palavras do pretenso profeta,

Homens afortunados thes trago a salvação, unam-se a nós e suas vidas serão salvas, sigamme e o terrivel mal não nos atingirá. Peguem suas armas e venham comigo à Terra Santa para libertar o Santo Sepulcro. Eu lhes prometo corpo e alma sãos. Será puro quem purificar o impuro, de todo mal irá sarar quem à Terra Santa comigo for. Vamos lá, soldados, de pé! Formem comigo um pelotão feliz. Todos para o Santo, Santo, Santíssimo Sepulcro. Deus assim quer. (trecho d'o Incrivel exército de Brancaleone, 1967, minuto 37)

Figura 4-O padre e os peregrinos

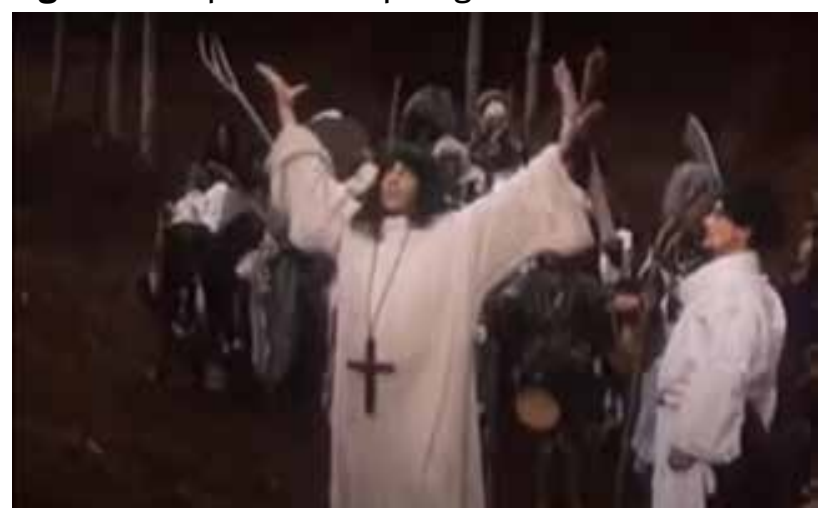

Fonte: Cena do filme $O$ incrivel exército de Brancaleone, $\min .39: 03$.

A romaria segue até encontrar uma ponte visivelmente precária. 0 medo da travessia foi motivo da dúvida na fé dos que seguiam o profeta. Quase todos atravessam a pon-

6 Termo apresentado por Oliveira (2012), coerente com o pensamento de Certeau que os chama somente de "praticantes", sem dicotomizar teoria e prática. Evidencia-se, assim, que estes criam conhecimentos-significações, permanentemente, no desenvolvimento de suas ações cotidianas. te, mas na última leva de romeiros a mesma cede, inflamando o beato a inquerir quem são os pagãos do grupo que motivaram a tragédia, castigo de Deus. Identificado, o "herege", foi logo batizado.

Os sentidos dessa obra podem ser atualizados com as tessituras de rizomas, ou seja, atravessados com outras narrativas na/da/ com a internet, como a de Edenilson Morais (2009): "utilizando-se sempre da sátira, o filme de Monicelli focaliza a decadência das relações sociais no mundo feudal, o poder da Igreja católica, o cisma do Oriente e a presença dos sarracenos". E continua, situando as questões das crenças: "as cruzadas entre os séculos XI e XIII representaram um outro revés para o feudalismo, já que Jerusalém não foi reconquistada pelos cristãos e o cristianismo não foi reunificado, com as igrejas Católica Romana e Ortodoxa permanecendo separadas" (2009, sem página). Morais (2009) contextualiza, em poucas palavras, então, o caráter religioso-satírico da película.

Insistimos nas "táticas de fazer crer" (CERTEAU, 1998, p. 286) que o filme permite entrever, diante da nossa incredulidade ao constatar que tais práticas-teorias perduram, através de séculos, e parecem se fortalecer na atualidade. Como exemplo dessa prática-teoria, podemos citar: os inúmeros pronunciamentos do atual presidente do Brasil em defesa do uso, aquisição e produção da hidroxicloroquina para o tratamento da COVID-19, mesmo sem pesquisas consolidadas; o uso precoce, ou como de forma preventiva, da ivermectina etc. Ambos os medicamentos e toda a difusão por meio de lives, palestras, notícias levaram a buscas desenfreadas às farmácias e são apenas alguns exemplos de práticas do que Certeau (1998) nos proporciona como reflexão quando escreve "a fabricação dos simulacros fornece assim o meio de produzir crentes e portanto praticantes" (Ibid., p. 287). 
Interessado em captar alguns dos funcionamentos do crer e do fazer, Certeau (1998, p. 286, grifos do autor) destaca dois dispositivos imprescindiveis para o ato de crer:

[...] falar em nome de um real que, supostamente inacessivel, é ao mesmo tempo o princípio daquilo que é crido (uma totalização) e o princípio do ato de crer (uma coisa sempre subtraída, inverificável, ausente); de outro lado, a capacidade do discurso, autorizado por um 'real' para se distribuir em elementos organizadores de práticas, isto é, em 'artigos de fé'. Essas duas forças tradicionais se acham hoje no sistema que combina na narratividade da mídia - uma instituição do real - o discurso dos produtos de consumo - uma distribuição desse real em 'artigos' que se devem crer e comprar.

$\mathrm{Na}$ profusão de ideias em que estamos imersos, os dados, os fatos, as informações são atravessados e entregues no conforto das nossas mãos, seja através de grupos de WhatsApp, de Facebook, através das mídias de massa, em conversas cotidianas informais apenas para citar alguns exemplos. Com os escritos de Certeau (1998, p. 287), notamos que os “ouvintes" seguem escutando "narratividades jornalísticas, publicitárias, televisionadas", o dia todo, todos os dias. Para ele, "essas histórias desempenham uma função de providência e predestinação: elas organizam de antemão nossos trabalhos, nossas festas e até os nossos sonhos" (Ibid., p. 288).

Perceba você, leitor, que cada praticante -pensante está imerso nesse jogo de crenças.

De repente, lançamo-nos no movimento de 'atualizar' as epidemias registradas na história da humanidade, através das quais pensamos o presente, como é o caso da peste na película em questão, além da gripe espanhola, da varíola, da chamada revolta da vacina, do surto de meningite etc. Todos esses dados históricos estão sendo revisitados constantemente e essa prática é considerada um movimento necessário: olhar para o passado e projetar o futuro, numa perspectiva acerca das políticas engendradas para atualidade, seja no combate à epidemia, seja em outras esferas da sociedade. Tais narrativas chegam a nós através de uma grande variedade de meios. Esse movimento apontado por Deleuze (2005) é inspirado em Henri Bergson, em muitos cineastas e autores que permitem pensar acerca da relação que estabelecemos com as imagens e o nosso tempo. Em suas palavras,

A própria imagem atual tem uma imagem virtual que a ela corresponde, como um duplo ou reflexo. Em termos bergsonianos, o objeto real reflete-se numa imagem especular como no objeto virtual que, por seu lado e ao mesmo tempo, envolve e reflete o real: há 'coalescência' entre os dois. Há formação de uma imagem bifacial, atual e virtual. É como se uma imagem especular, uma foto, um cartão postal, se animassem, ganhassem independência e passassem para o atual, com o risco de a imagem atual voltar ao espelho, retomar lugar no cartão postal ou na foto, segundo um duplo movimento de liberação e de captura (DELEUZE, 2005, p. 87-88).

O movimento de engendrar pesquisas por meio de narrativas presentes na internet sobre Brancaleone e, seu exército maltrapilho, a linguagem das sátiras, as críticas - algumas de cunho simplista comparando o filme à obra dos Trapalhões no Brasil, voltada a um público infantojuvenil - desembocou na atualização do virtual, que para Deleuze (2005) são imagens indiscerníveis:

Não há virtual que não se torne atual em relação ao atual, com este se tornando virtual sob essa mesma relação: são um avesso e um direito perfeitamente reversíveis. São 'imagens mútuas', como diz Bachelard, nas quais se efetua uma troca. A indiscernibilidade do real e do imaginário, ou do presente e do passado, do atual e do virtual, não se produz portanto, de modo algum, na cabeça ou no espírito, mas é o caráter objetivo de certas imagens existentes, duplas por natureza (Ibid., p. 89). 
Ocorrem muitas interferências na compreensão de uma obra filmica, quando recorremos à crítica em geral. Nesse percurso, tivemos contato com críticas tecidas em diferentes anos desde que o filme foi lançado. As redes trançadas naquele espaço-tempo eram outras e ainda mais específicas de acordo com as autorias. A “internet não perdoa" é uma máxima que tem seu efeito, ao passo que também é preciso compreender que as imagens, sons, narrativas são criadas a partir de universos individuais, por um lado, e coletivo por outro, à medida que atravessamos os "agenciamentos" (DELEUZE; GUATTARI, 1996) de outros e muitos são os nossos “intercessores” (Id., 1992).

\section{Considerações finais: caminhos entre cinema, memória e formação}

À guisa de conclusão, retomamos aqui alguns objetivos que esperamos terem sido alcançados ao longo da escritura deste artigo. É claro que deixamos um convite aos leitores para a tessitura dessas redes. Um possível visionamento do filme para quem ainda não conhece a obra, sem dúvida enriqueceria a leitura. No entanto, nosso objetivo foi dialogar através de cineconversas com o filme e com algumas situações que se apresentam nos cotidianos de uma pandemia, como distanciamento social, fechamento de escolas, universidades, entre outras situações de privação do ir e vir.

Muitos questionamentos acerca do tempo desse filme atravessaram esse retorno e essa busca, inicialmente simples, ao 0 incrivel exército de Brancaleone, os principais foram, como já abordado, relativos à atualidade das questões do filme, os comportamentos das populações famigeradas e desesperadas por milagres e cura, a precariedade de um sistema político e econômico ainda vigente em muitos países, inclusive no nosso, o uso do termo "Branca- leone" para caracterizar diferentes grupos e situações etc. Nessa busca por atualização de narrativas, imagens e sons, surgem receios de supostas idealizações, realidades, ficções, invenções, falsidades... No entanto,

Se Bergson chama a imagem virtual de 'lembrança pura', é para melhor distingui-la das imagens mentais, das imagens-lembrança, sonho ou devaneio, com as quais corremos o risco de confundi-la. Com efeito, estas são imagens virtuais, mas atualizadas ou em vias de atualização em consciências ou estados psicológicos. E elas se atualizam necessariamente com referência a um novo presente, a outro presente que não aquele que foi (DELEUZE, 2005, p. 100).

É nesse sentido que se dão as cineconversas nas pesquisas que desenvolvemos com docentes-discentes em cursos de formação de professores: tecemos com os praticantes -pensantes da pesquisa e extensão conhecimentos-significações com as imagens e sons que atualizamos a cada vez que vemos-ouvimos-sentimos um determinado filme. E foi assim também com as pesquisadoras que criaram este artigo. Desafiadas pelo isolamento em decorrência da conjuntura da pandemia, propusemo-nos a inventar outras maneiras de tecer conhecimentos-significações, através de filmes no grupo de pesquisa ao qual pertencemos. Quem sabe uma saída para permanecer em contato com o mundo, como sugere Deleuze (2005, p.87): "o cinema não apresenta apenas imagens, ele as cerca com um mundo". Algumas táticas de resistência, resiliência, sobrevivência e criação - afinal, como viver sem as artes? - foram inventadas nos usos que fomos, lance por lance, aprendendo-fazendo nesse não tão novo modo de ser e estar on-line e virtual.

Optamos por assistir a títulos previamente acordados entre o grupo e, em especial, as autoras, seguindo para conversas, através de reuniões em plataformas de reuniões on-line. 
Acreditamos que permanecer em contato através das telas e dos emaranhados cabos de fibra -ótica foi uma saída para permanecer criando coletivamente, como nos rizomas, em outras palavras, tecendo redes educativas. É como se tecêssemos uma enorme rede sem início, meio e fim. Laçamos, cruzamos, cerzimos, atravessamos fios um a um, a partir das vivências e experiências singulares, disparadas através de nossas memórias e conexões possíveis. Porque o cinema potencializa o pensamento e a tessitura das redes sem fim.

\section{Referências}

ALVES, Nilda. Decifrando o pergaminho - o cotidiano das escolas nas lógicas das redes cotidianas. In: OLIVEIRA, Inês Barbosa; ALVES, Nilda. Pesquisa no/ do cotidiano das escolas - sobre redes de saberes. Rio de Janeiro: DP\&A, 2008. p. 15-38.

ALVES, Nilda; FERRAÇO, Carlos Eduardo. Conversas em redes e pesquisas com os cotidianos. In: RIBEIRO, Tiago; SOUZA, Rafael; SAMPAIO, Carmen Sanches (orgs). Conversa como metodologia de pesquisa: por que não? Rio de Janeiro: Ayvu, 2018. p.41-64.

ALVES, Nilda; ANDRADE, Nívea; CALDAS, Alessandra. Os movimentos necessários às pesquisas com os cotidianos - após muitas conversas acerca deles. In: OLIVEIRA, Inês Barbosa; PEIXOTO, Leonardo Ferreira e SÜSSEKIND, Maria Luiza (orgs). Estudos do cotidiano, currículo e formação docente: questões metodológicas, políticas e epistemológicas. Curitiba: CVR, 2019. p. 19-40.

BRAGANÇA, Inês Ferreira de Souza. Histórias de vida e formação de professores: diálogos entre Brasil e Portugal. Rio de Janeiro: EdUERJ, 2012.

BRANDÃO, Vera M. A. T. Labirintos da memória: quem sou eu? São Paulo: Paulus, 2008.

DE CERTEAU, Michel. A invenção do cotidiano: 1. Artes de fazer. Petrópolis, RJ: Vozes, 1994.

DE CERTEAU, Michel. A invenção do cotidiano: 1. Artes de fazer - 3a ed. Petrópolis, RJ: Vozes, 1998.

DELEUZE, Gilles. A imagem-tempo (Cinema 2). São
Paulo: Brasiliense, 2005.

DELEUZE, Gilles. A imagem-movimento (Cinema 1). São Paulo: Brasiliense, 1985.

DELEUZE, Gilles; GUATTARI, Félix. Os personagens conceituais. In: DELEUZE, Gilles; GUATTARI, Félix. 0 que é filosofia? Rio de Janeiro: Editora 34, 1992. p. 75-102.

Deleuze, Gilles; GuATTARI, Félix. Mil Platôs: Capitalismo e Esquizofrenia. V.1. Rio de Janeiro: Ed. 34, 1996.

GUERÓN, Rodrigo. Da imagem ao clichê do clichê à imagem: Deleuze, cinema e pensamento. Rio de Janeiro: FAPERJ, Nau editora, 2011.

JOSSO, Marie-Christine. Experiências de vida e formação. Lisboa: Educa, 2002.

MORAIS, Edenilson. 0 incrivel exército de Brancaleone - Uma sátira da cavalaria medieval europeia. Disponivel em: http://mestresdahistoria.blogspot. com/2009/09/o-incrivel-exercito-de-brancaleone -uma.html. Acesso em: 20 Jul. 2020.

O INCRÍVEL EXÉRCITO DE BRANCALEONE. Filme dirigido por: Mario Monicelli. Com: Vittorio Gassman, Catherine SpaakFolco Lulli, Gian Maria Volonté. Itália, 1967, colorido, 124 min. Disponível em: https:// www.youtube.com/watch?v=lCzH0LMRs98. Acesso em 20 jul. 2020. (Filme).

OLIVEIRA, Inês Barbosa de. Currículos e pesquisas com os cotidianos: o caráter emancipatório dos currículos 'pensadospraticados' pelos 'praticantespensantes' dos cotidianos das escolas. In: Carlos Eduardo Ferraço e Janete Magalhães Carvalho (Org.). Currículos, pesquisas, conhecimentos e produção de subjetividades. Petrópolis: DP et Alii, 2012. p. 47-70.

PASSEGGI, Maria da Conceição; BARBOSA, Tatyana Mabel Nobre (Orgs.). Narrativas de formação e saberes biográficos. Natal, RN: EDUFRN; São Paulo: Paulus, 2008.

SOUZA, Eliseu Clementino; RIBEIRO, Neurilene Martins. As cartas e as histórias de vida: dilemas e aprendizagens da docência em língua portuguesa. In: OLI- 
VEIRA, Inês Barbosa (Org.). Narrativa: outros conhecimentos, outras formas de expressão. Petrópolis, RJ: DP et Alii; Rio de Janeiro: FAPERJ, 2010. p. 79-95.

WILDER, Laura Ingalls. A casa na floresta. Rio de Janeiro: Editora Record, 1963.
WILDER, Laura Ingalls. Às margens da lagoa pratea-

da. Rio de Janeiro: Editora Record, 1963.

Recebido em: 28/07/2020

Revisado em: $12 / 12 / 2020$

Aprovado em: 14/12/2020

Rebeca Silva Brandão é doutora e mestre em Educação pelo Programa de Pós-Graduação em Educação (ProPEd) da Universidade do Estado do Rio de Janeiro (UERJ), pedagoga pela UERJ, professora da rede de ensino do município do Rio de Janeiro, mediadora do Centro de Educação a distância do Estado do Rio de Janeiro (CEDERJ) da UERJ. Membro do GRPesq “Currículos cotidianos: redes educativas, imagens e sons”. E-mail: rebecasbr@gmail.com

Rosa Helena Mendonça é doutora em Educação pelo Programa de Pós-Graduação em Educação (ProPEd) da Universidade do Estado do Rio de Janeiro (UERJ). Atuou como professora na rede municipal de ensino do Rio de Janeiro e na Universidade Estácio de Sá. Coordenou a equipe pedagógica da TV Escola do Ministério da Educação (MEC). Integra o Grupo de Pesquisa Currículos cotidianos: redes educativas, imagens e sons do ProPEd da UERJ), como bolsista do Programa Nacional de Pós-Doutorado (PNPD) da Coordenação de Aperfeiçoamento de Pessoal de Nível Superior (Capes) e Fundação de Amparo à Pesquisa do Estado do Rio de Janeiro (Faperj), em estágio pós-doutoral. E-mail: rhmen50@gmail.com

Rossana Papini é doutora em Educação pelo Programa de Pós-Graduação em Educação (ProPEd) da Universidade do Estado do Rio de Janeiro (UERJ). É professora Adjunta da Universidade Federal Fluminense (UFF), atuando no Instituto do Noroeste Fluminense de Educação Superior (Infes), junto ao Departamento de Ciências Humanas (PCH). Integra o GRPesq Currículos cotidianos: redes educativas, imagens e sons da ProPEd da UERJ. E-mail: rmpapini2009@hotmail.com 